\title{
Study of Forces during Micro-Assembly Tasks using Two-Sensing-Fingers Grippers
}

\author{
Kanty Rabenorosoa, Cédric Clévy, Qiao Chen, and Philippe Lutz, Member, IEEE
}

\begin{abstract}
In this paper, the use of a two-sensing-fingers gripper for grasping planar microparts (smaller than $0.1 \mathrm{~mm}^{3}$ ) is being investigated and the force range during a micro-assembly sequence is estimated between 0 to $3 \mathrm{mN}$. An analytical model of their gripping forces in the presence of a lateral contact force is proposed and it is compared to FEA (Finite Element Analysis). An experimental validation is performed by a proposed setup for a lateral contact force in the range of a few tens to hundreds of $\mu \mathrm{N}$. Effects of the variation of parameters like the distance of contact, the thickness of the finger, the compliance of the finger and the preload are investigated. Design statements of microgripper and the applied force range are given in order to achieve automated micro-assembly tasks.
\end{abstract}

Index Terms-Micro-assembly, microrobotics, planar micropart, two-sensing-fingers, gripping forces, lateral contact, compliance.

\section{INTRODUCTION}

D URING the last decade, the need of micronanotechnology has become an important challenge [1]. Recent developments have showed that micro-assembly is a possible response for hybrid 3D microsystems design [2], [3], [4]. In order to succeed in robotic micro-assembly, tools and systems which ensure gripping, releasing, precise positioning, feeding, and joining have been developed. Many researches have been concentrated on the design of the microgripper due to its importance for handling micro-objects [5], [6], [7], [8]. A comparison of microgripper principles is proposed in [7], it has been shown that 11 kinds of microgripper principles can be distinguished but complete automated micro-assembly requires force control (active or passive) and cycle time, thus, some of them do not suit these conditions. A microgripper based on a pair of fingers or jaws can be used, consequently it is chosen. This kind of microgripper ensures friction contact with the object to-be-gripped. Additionally, its flexibility and recent micro-assembly results in [2], [4], [6], [9] confirm its efficiency. The state of the art of two-fingers microgrippers is focused on four points: the structure of the microgripper [2], [10], [11], [12], the actuation [13], [14], [12], [15], the sensing [16], [17], [15], [18] and their control [19], [20], [21]. Despite numerous works, tasks like accurate positioning of manipulated microparts and automated micro-assembly, remain difficult.

In literature, it has been shown that force guided microassembly constitutes a relevant approach [22]: it enables

K. Rabenorosoa, C. Clévy and P. Lutz are with FEMTO-ST Institute, UMR CNRS 6174 - UFC / ENSMM / UTBM, Automatic Control and MicroMechatronic Systems Department, 25000 Besançon, France, Q. Chen is now working with Jinshan Sciences \& Technology, China (e-mail: rkanty@femtost.fr, cclevy@femto-st.fr, chenq@jinshangroup.com, plutz@femto-st.fr.) to obtain local and useful information like contact and adhesion forces. For example, gripping forces provide useful information which is relative to the loss or the break of microparts or micromanipulators. To achieve accurate positioning, it is also possible to take into account contact perturbations especially pull-off forces [23].

Force control has already been applied to achieve stable grasping [16], [24], [15], peg in hole insertion [25], [26], [27], [28], lift mirror [29], [30], and alignment by pushing [31]. Despite interesting results, these works are not applicable to the assembly of silicon components with planar surfaces whereas they are the most widespread [3], [4], [32] because it requires:

- the control of lateral contact forces,

- the fine modeling of the manipulated object behavior when subjected to external forces (contact forces cannot be directly measured during the assembly),

- suitable design of the microgripper.

These requirements lead to extremely challenging topics like force sensors integration, understanding of the behavior of the manipulated micro-object subjected to the adhesion forces when observation and the measurements of parameters are extremely complex.

To successfully achieve complex micro-assembly tasks of planar silicon components, these topics are addressed in this paper. The knowledge of the micropart displacement and interaction forces between a grasped micropart and its environment is notably enhanced during the micro-assembly. The effect of lateral contact force on a grasped micropart is investigated for the first time.

In addition, despite active researches in microgripper and force guided assembly, neither recommendation for microassembly tools design nor applied force range are established on the microscale. Indeed, technological limitations (material, process compatibility, etching deep, photoresist resolution, read out capability...) are generally used for designing tools especially for force sensors and sensing microgrippers. The study proposed in this paper consisting in a new approach based on task constraints will also conduct to define the applied force range and recommendations on microgripper design (type of contact, compliance).

This paper presents the study of a microgripper with twosensing-fingers for micro-assembly. It is focused on the evolution of gripping forces in the presence of lateral contact force for the manipulation of planar microparts. The paper is organized as follows. Section II presents the context of grasping with two-sensing-fingers. Section III describes the model of grasping forces in the presence of lateral contact 
force. Effects of the variation of parameters are presented in section IV. Section V discusses the consequences on the design of microgrippers and the applied force range through statements. Finally section VI concludes the paper.

\section{GRASPING MICROPART WITH TWO-SENSING-FINGER MICROGRIPPER}

Micro-assembly consists of tasks like picking, moving, inserting into a hole (or a groove), guiding in a rail, holding a position during joining and releasing. The control of forces, especially gripping forces can improve the success rate of these tasks. To perform such tasks, the microgripper configuration has to be considered. A microgripper based on two-sensingfingers is proposed (see Fig. 1) to control the gripping and all the tasks described above. It constitutes a flexible gripping principle (various successive tasks) and enables to estimate the lateral contact force through information from two fingers [33]. Additionally, the fine control of micro-assembly steps can be achieved and force measurement efficiently contributes to the automation of tasks. Each finger of the proposed microgripper has a probe with a planar surface at its tip (i.e. planar contact between the microgripper and microparts, Fig. 1). To ensure grasping, the fingers are moved by $X_{i} Y_{i} Z_{i}$ positioning stages and the motion along $\mathrm{Y}$ establishes initial gripping forces named preload forces. The microgripper has $K_{x_{i}}, K_{y_{i}}, K_{z_{i}}$ stiffness for each finger. A model of the microgripper is proposed with the sensing axis along $Y$ represented by $K_{y_{i}}$ spring stiffness, $K_{x_{i}}$ and $K_{z_{i}}$ integrated to the probe behaviour (see Fig. 2). Each probe can move along $Y$ to measure $F_{y_{i}}$ and can bend along $Z$ due to flexure force $F_{z_{i}}$. Firstly the pick operation is studied.

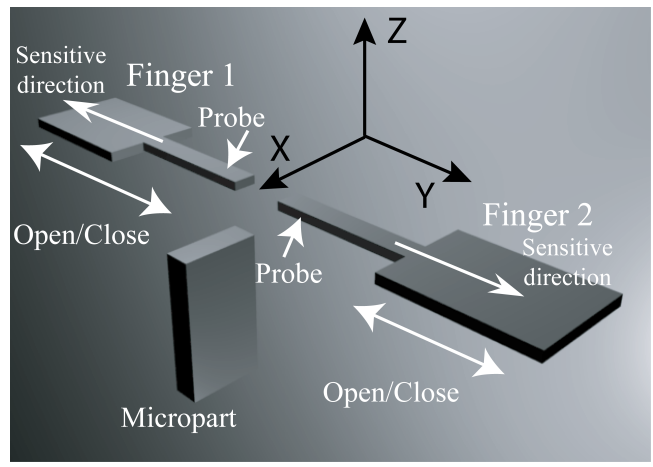

Fig. 1. Principle of a microgripper based on two-sensing-fingers.

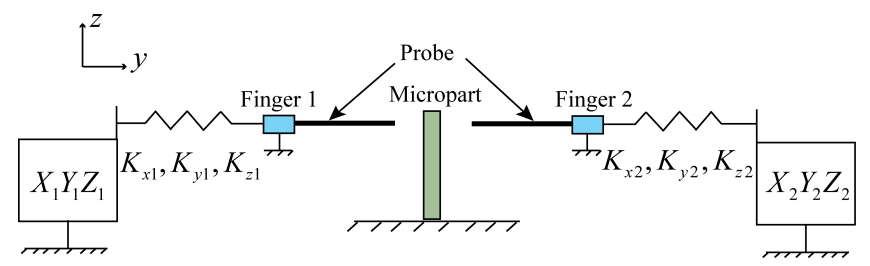

Fig. 2. Model of the microgripper with its two fingers consisting in FemtoTools $®$ sensors.

\section{A. Preload expression according to the displacement of each} finger

Preload corresponds to the initial force applied on both sides of the micropart by the fingers of the microgripper. They enable the micropart to be held thanks to the friction principle. In a first stage, we consider perfect surfaces in contact, without any misalignment, the micropart is positioned in the middle of both fingers. According to the geometric scheme (see Fig. 3), $d_{f_{i}}=d_{f_{1}}=d_{f_{2}}$ is the distance between the micropart side and the tip of the finger $i$. If the displacement of each finger is $\Delta_{f_{1}}=\Delta_{f_{2}}$ and $\Delta_{f_{i}} \geq d_{f_{i}}$, consequently, $F_{y_{1}}=F_{y_{2}}=K_{y}\left(\Delta_{f_{i}}-\right.$ $d_{f_{i}}$. When tips do not touch micropart sides, $F_{y_{1}}=F_{y_{2}}=0$.

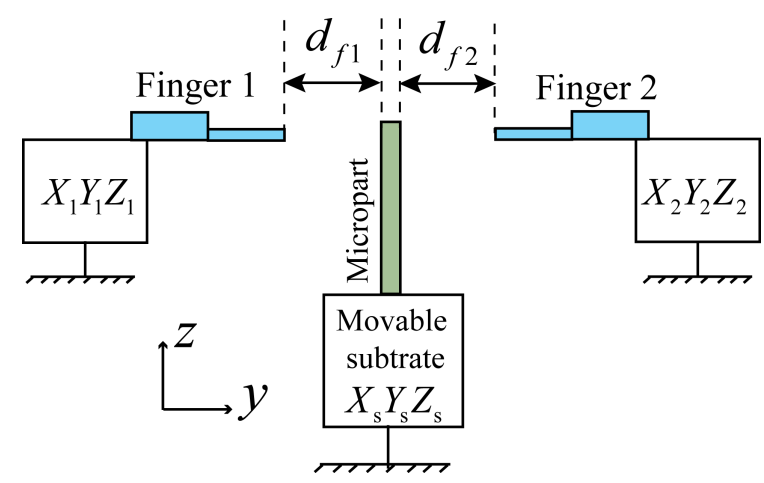

Fig. 3. Geometric scheme of the microgripper before applying the preload.

We introduce the misalignment of fingers and define tilt angles in $Y_{p} Z_{p}$ plane $\left(\alpha_{x}\right)$ and $X_{p} Y_{p}$ plane $\left(\alpha_{z}\right)$. Based on
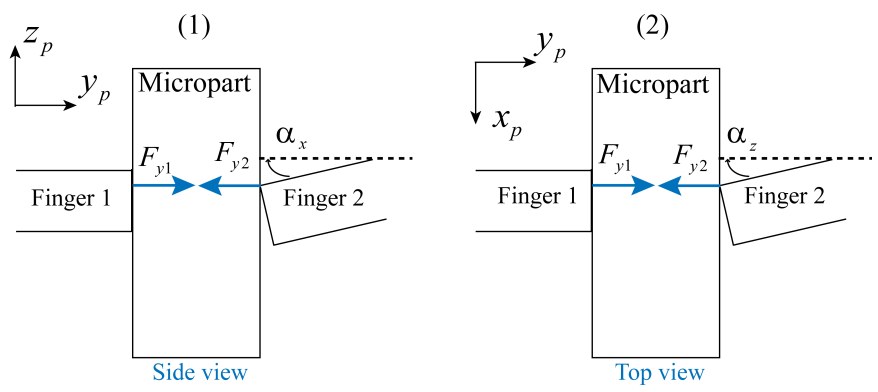

Fig. 4. Misalignment of the probe in the plane $Y_{p} Z_{p}$ (1) and the plane $X_{p} Y_{p}$ (2).

Fig. 4, the forces equilibrium gives $F_{y 1}=F_{y 2}$. Let us note that $F_{s 1}$ and $F_{s 2}$ are the sensor information respectively from Finger 1 and Finger 2. Taking into account the misalignment between fingers like Fig. 4, we obtain $F_{y 1}=F_{s 1}$ and $F_{s 2}=$ $F_{y 2} \cos \alpha_{x} \cos \alpha_{z}$. The difference between gripping force $F_{s 1}$ and $F_{s 2}$ is $\Delta_{F}=F_{s 1}\left(1-\cos \alpha_{x} \cos \alpha_{z}\right)$. It is negligible if tilt angles, $\alpha_{x}$ and $\alpha_{z}$, are smaller than $5^{\circ}$ (see Table I).

\section{B. Pick condition}

The micropart is initially placed on the substrate. For succeeding the pick operation, static equations are derived by taking into account that the weight is negligible. When a relative motion along $Z$ is generated between the substrate and the micropart to separate them, the grasping forces have to overcome adhesion forces between the micropart and the 


\begin{tabular}{|c|c|c|}
\hline$F_{s 1}$ & $\alpha_{x}=\alpha_{z}$ & $\Delta_{F}$ \\
\hline 1000 & 0.5 & $0.07 \mu \mathrm{N}$ \\
\hline 1000 & 2.5 & $1.90 \mu \mathrm{N}$ \\
\hline 1000 & 5 & $7.59 \mu \mathrm{N}$ \\
\hline
\end{tabular}

TABLE I

DIFFERENCE BETWEEN $F_{s 1}$ AND $F_{s 2}$ IN THE PRESENCE OF MISALIGNMENT.

substrate. Fig. 5 illustrates a simplified body diagram that is used to obtain force equations and pick conditions. Let us note

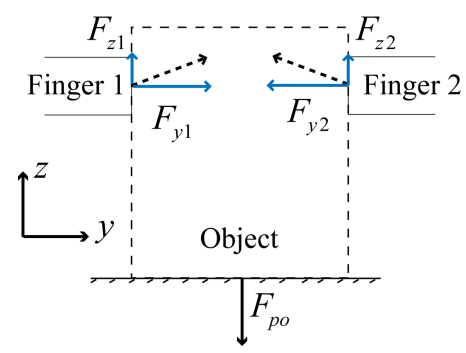

Fig. 5. Gripping force for succeeding pick operation.

that $F_{y 1}$ and $F_{y 2}$ are applied forces by Finger 1 and Finger 2 to the object along $\mathrm{Y}, F_{z 1}$ and $F_{z 2}$ are forces induced by friction, and $\mu$ the friction coefficient. When the equilibrium of the micropart is studied, the Coulomb model gives:

$$
\begin{gathered}
F_{y 1}=F_{y 2} \\
F_{z 1}=\mu F_{y 1} \\
F_{z 2}=\mu F_{y 2}
\end{gathered}
$$

$F_{p o}$ is the pull-off force defined as the necessary force for breaking the contact between the substrate and the micropart. The condition of the pick (removing the contact between the micropart and substrate) is :

$$
F_{z 1}+F_{z 2}>F_{p o}
$$

Using (2), (3), and (4), we can write:

$$
\mu F_{y 1}+\mu F_{y 2}>F_{p o}
$$

In reference to [23], the pull-off force can reach $196 \mu \mathrm{N}$ for planar silicon contacts (with $50 \mu \mathrm{m} \times 50 \mu \mathrm{m}$ of surface). This value depends on the surface in contact and the characteristics of the surfaces, especially the roughness and their relative orientation. Considering the coefficient of friction and the pulloff force between the micropart and the substrate, minimum values of gripping forces for succeeding pick operation are listed in Table II.

\section{Apparition of lateral contact during micro-assembly tasks}

During micro-assembly, lateral contact on the grasped micropart often appears. Figure 6 displays four examples of tasks where the control of the lateral contact force constitutes helpful information for achieving the task.

The comprehension of the gripping force variation is proposed in the following.

\begin{tabular}{|c|c|}
\hline Friction coefficient & Minimum grasping forces \\
\hline 0.1 & $980 \mu \mathrm{N}$ \\
\hline 0.2 & $480 \mu \mathrm{N}$ \\
\hline 0.3 & $326.6 \mu \mathrm{N}$ \\
\hline
\end{tabular}

TABLE II

MINIMUM VALUES OF GRASPING FORCE ACCORDING TO THE FRICTION COEFFICIENT FOR $196 \mu \mathrm{N}$ PULL-OFF FORCES CONSIDERING $50 \mu \mathrm{M}$ X 50 $\mu \mathrm{M}$ OF SURFACE OF CONTACT.
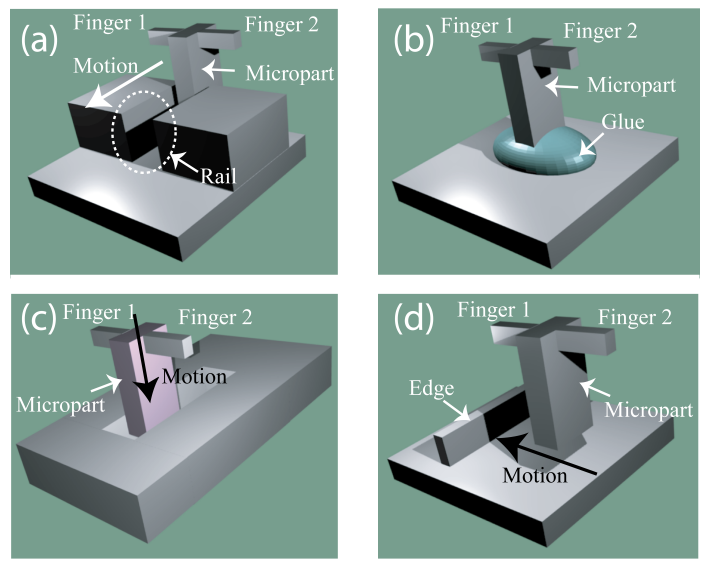

Fig. 6. (a) guiding task (move forward along the rail and control of the contact force between the rail side and the micropart, (b) position control during joining, (c) insertion with one axis constraint, (d) positioning using edge reference.

\section{GRASPING FORCES IN THE PRESENCE OF LATERAL CONTACT FORCE}

The objective of this section is to obtain the influence of the microgripper parameters on the evolution of the gripping forces. A static model of gripping forces in the presence of a lateral contact force is proposed. The validation of the model is proposed through the comparison to FEA and experimental results. The objective of these model investigations is to understand the influence of the microgripper's parameters on the evolution of the gripping forces and the behavior of the grasped micropart in order to achieve automated microassembly.

\section{A. Analytical model}

In the presence of a lateral contact force, the equilibrium of the gripping forces changes like the contact between the micropart and the tips of the microgripper. This lateral contact force appears when the grasped object is in contact with its environment and creates a force $F=\left\{F_{x}, F_{y}, F_{z}\right\}$ at a distance $\ell$. We assume that the components of $F$ along $X$ and $Z$ are negligible. The evolution of the gripping forces $\left(F_{y 1}\right.$ and $F_{y 2}$ ) is studied according to the contact force $F_{y}$ (see Fig. 7). The model of the microgripper shown in Fig. 2 is used with the parameters below:

- $K_{y_{i}}$ is the stiffness along the sensing axis represented by the spring,

- $K_{x_{i}}$ and $K_{z_{i}}$ are the stiffness of the probe,

- $t_{f}$ the thickness of the finger,

- $L_{p}$ the length of the probe of the finger, 
- $w_{p}$ the width of the probe of the finger,

- E the Young modulus of the material,

- $\mathrm{I}=\frac{w_{p} t_{f}^{3}}{12}$ the probe second moment of area,

- $w_{m}$ the width of the micropart.

We define $\Delta_{y i}$ as the displacement of the finger $i=1,2$ along $Y$ due to the spring $K_{y_{i}}$ and $\Delta_{z i}$ the displacement of the finger $i=1,2$ along $Z, \Delta_{y f i}$ is the decrease along $Y$ of the sensor probe due to its bending, $F_{z a}=F_{z 1}=F_{z 2}$ the induced force of friction along $\mathrm{Z}$. The displacements of points $\mathrm{A}$ and $\mathrm{B}$ are described by $\left\{\Delta_{y i}+\Delta_{y f i}, \Delta_{z i}\right\}$.

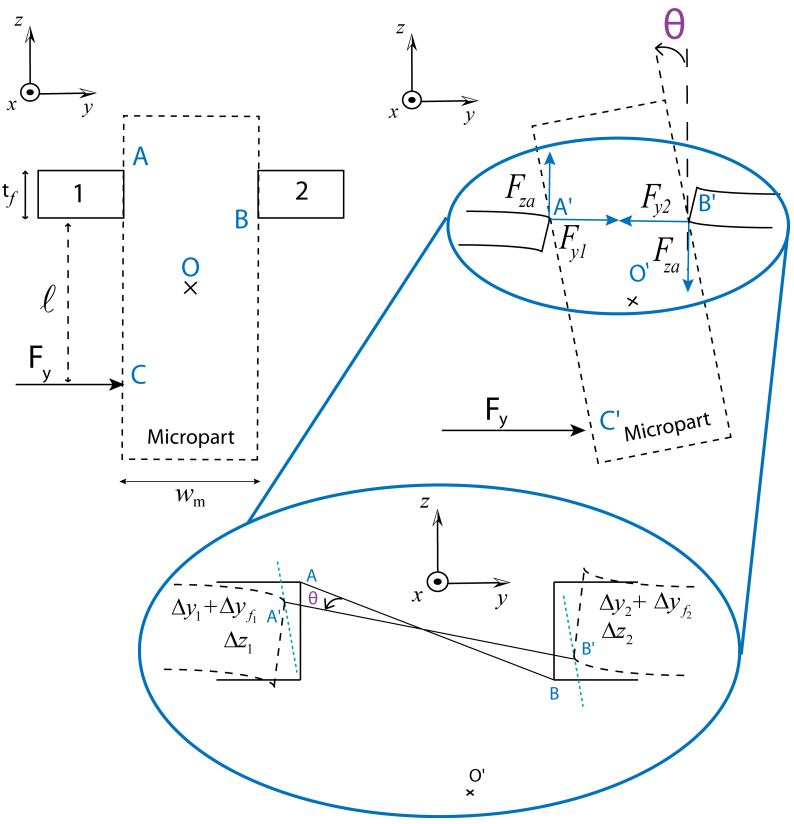

Fig. 7. Grasp before and after the appearance of an external force perturbation $F_{y}$ (front view).

The gripping is divided into 3 steps: the initial situation (before external contact) - step 1 and the appearance of the lateral contact force that induces two steps of micropart motion: linear motion - step 2 and combined linear/rotation motion - step 3 (see Fig. 8).

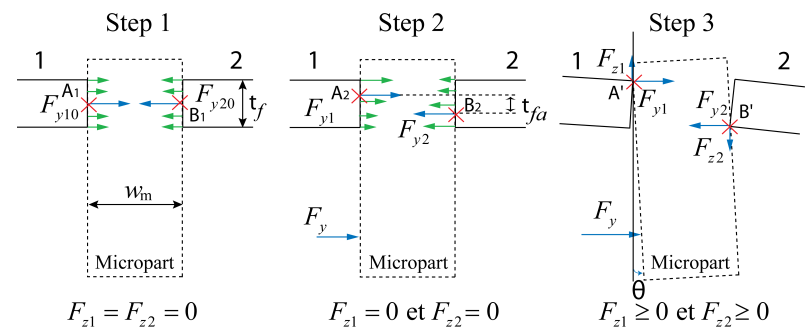

Fig. 8. Grasping contact evolution in the presence of a lateral contact force: (Step 1) the lateral contact force $F_{y}=0$, (Step 2) constitutes the planar contact between the micropart and finger tips in the presence of lateral contact force $F_{y} \neq 0,(3)$ represents edge-vertex contact.

1) Planar contact between the micropart and finger tips: During Step 1, no external force is applied to the micropart and perfect planar contact occurs between the grasped micropart and finger tips. An equal repartition of stress is observed at each finger tip. Thus, the equivalent force is considered at the center of each finger tip $\left(A_{1}-B_{1}\right)$. In Step 2, the appearance of a lateral contact force induces an imbalance of constraints. Equivalent forces move from the center to the edge of the tip (the distance between $A_{2}$ and $B_{2}$ along $\mathrm{Y}$ is the apparent thickness $t_{f a}$ ) and the micropart is in a linear displacement along Y. During this step, we assume that $\Delta_{z i}=0$ due to the plane/plane contact and the stiffness along $\mathrm{Z}$. The continuity between Step 2 and Step 3 is ensured when equivalent forces are localized on opposite edges of each finger $\left(A^{\prime}-B^{\prime}\right)$ and consequently the lateral contact force limit $F_{y \ell}(6)$ depends on the preload force $F_{y 10}=F_{y 20}$, the thickness of the finger $t_{f}$ and the distance of the contact $\ell$. The expression of $F_{y \ell}$ is given by:

$$
F_{y \ell}=F_{y i 0}\left(\frac{2 t_{f}}{2 \ell+t_{f}}\right)
$$

During this step, the following gripping forces are:

$$
F_{y 1}=F_{y 10}-\frac{F_{y}}{2}, F_{y 2}=F_{y 20}+\frac{F_{y}}{2}
$$

2) Edge-Vertex contact between the micropart and finger tips: During Step 3, the lateral contact force is bigger than $F_{y \ell}$. A complex motion of the object happens. To calculate gripping forces, a system of 5 equations enables to be determined $\Delta_{y 2}$, $\Delta_{y 1}, \Delta_{z}=\Delta_{z i}, F_{z a}$, and $\Delta_{y f}=\Delta_{y f i}$.

The equilibrium of forces along $\mathrm{Y}$ gives:

$$
F_{y}=K_{y}\left(\Delta_{y 2}-\Delta_{y 1}\right)
$$

Considering the pseudo-rigid body assumption [34], the expression of the probe bending along $\mathrm{Z}$ gives:

$$
\Delta_{z}=0.85 L_{p} \sin \left(\frac{0.85 F_{z a} L_{p}^{2}}{2.25 E I}\right)
$$

The decrease along $Y$ of the sensor probe [34] due to its bending gives:

$$
\Delta_{y f}=0.85 L_{p}\left(1-\cos \left(\frac{0.85 F_{z a} L_{p}^{2}}{2.25 E I}\right)\right)
$$

The torque equilibrium at point $A^{\prime}$ (Fig. 7) gives:

$$
\begin{gathered}
\overrightarrow{F_{y}} \wedge \overrightarrow{C^{\prime} A^{\prime}=} \overrightarrow{F_{z a}} \wedge \overrightarrow{B^{\prime}} A^{\prime}+\overrightarrow{F_{y 2}} \wedge \overrightarrow{B^{\prime} A^{\prime}} \\
F_{y}\left(\ell+t_{f}-\Delta_{z}\right)=F_{z a}\left(w_{m}+\Delta_{y 1}+\Delta_{y 2}+2 \Delta_{y f}\right) \\
+\left(F_{y 20}+K_{y} \Delta_{y 2}\right)\left(t_{f}-2 \Delta_{z}\right)
\end{gathered}
$$

The condition of non sliding of the object, $\|\overrightarrow{A B}\|=\left\|\overrightarrow{A^{\prime} B^{\prime}}\right\|$ gives:

$4 t_{f} \Delta_{z}-4 \Delta_{z}^{2}=\left(\Delta_{y 1}+\Delta_{y 2}+2 \Delta_{y f}\right)^{2}+2 w_{m}\left(\Delta_{y 1}+\Delta_{y 2}+2 \Delta_{y f}\right)$

The numerical resolution of this nonlinear system gives the evolution of the gripping forces according to the applied contact force in Fig. 9. These curves show two steps (Step 2 of linear motion and step 3 of combined linear/rotation motion) of the evolution of the gripping forces. It is observed that gripping forces are around $2250 \mu \mathrm{N}$ for $100 \mu \mathrm{N}$ of lateral contact force. If we define the maximum distance of contact at $\ell=1500 \mu \mathrm{m}$, they can reach $3 \mathrm{mN}$ for $100 \mu \mathrm{N}$ of lateral contact force. 


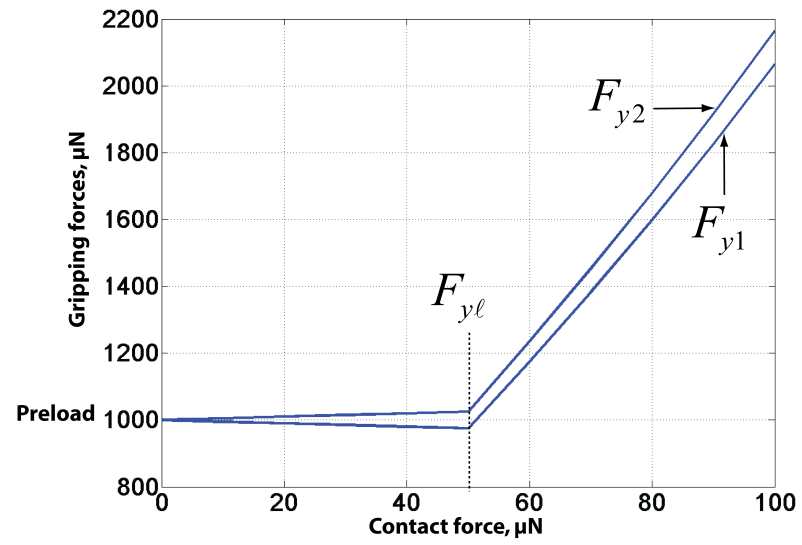

Fig. 9. The evolution of the gripping forces according to $F_{y}$ with $F_{y 10}=$ $F_{y 20}=1000 \mu \mathrm{N}, \ell=975 \mu \mathrm{m}, w_{m}=100 \mu \mathrm{m}, t_{f}=50 \mu \mathrm{m}, K_{y}=1000 \mathrm{~N} / \mathrm{m}, \mathrm{E}=170$ $\mathrm{GPa}, L_{p}=3000 \mu \mathrm{m}, w_{p}=300 \mu \mathrm{m}$.

B. Relation between the displacement of the contact point $\Delta_{y F}$ and the lateral contact force $F_{y}$

The lateral contact force appears when the micropart comes into contact with its environment (substrate, hole, groove, rail...). Considering the case of rigid environment, the rotation angle $\theta$ of the micropart in the $Y Z$ plane can be estimated by (14) and (15) where $\Delta_{y F}$ is the lateral displacement of the micropart at the contact point.

$$
\begin{gathered}
\tan \theta=\frac{\Delta_{y F}}{\ell+t_{f}-\Delta z} \\
\theta=\operatorname{atan}\left(\frac{t_{f}}{w_{m}}\right)-\operatorname{atan}\left(\frac{t_{f}-2 \Delta_{z}}{w_{m}+\Delta_{y 1}+\Delta_{y 2}+2 \Delta_{y F}}\right)
\end{gathered}
$$

The combination of (14) and (15) gives the expression of $\Delta_{y F}$ according to $t_{f}, w_{m}, \ell, \Delta_{y 1}, \Delta_{y 2}, \Delta_{z}, \Delta_{y f}$. The evolution of the angle $\theta$ and $\Delta_{y f}$ is presented in Fig. 10. The
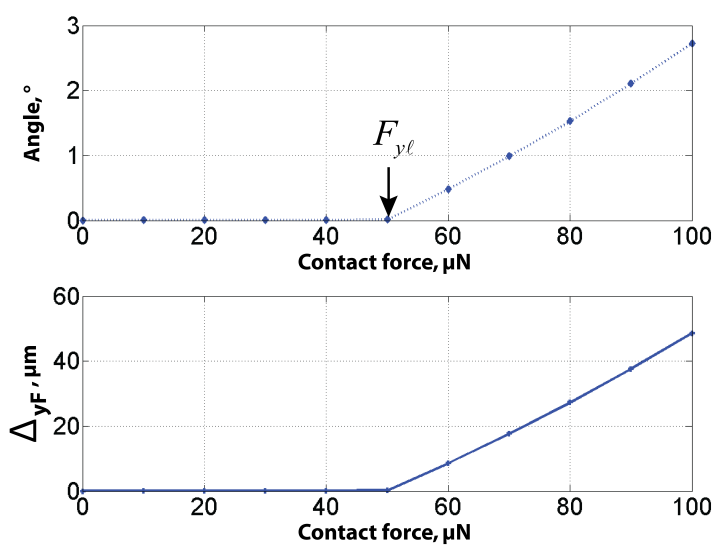

Fig. 10. Angle $\theta$ and $\Delta_{y F}$ evolution according to $F_{y}$ with $F_{y 10}=$ $F_{y 20}=1000 \mu \mathrm{N}, \ell=975 \mu \mathrm{m}, w_{m}=100 \mu \mathrm{m}, t_{f}=50 \mu \mathrm{m}, K_{y}=1000 \mathrm{~N} / \mathrm{m}, \mathrm{E}=170$ $\mathrm{GPa}, L_{p}=3000 \mu \mathrm{m}, w_{p}=300 \mu \mathrm{m}$.

angle position $\theta$ can also be estimated. The accuracy of the estimated value depends on the distance of contact $\ell$ and the misalignment of the fingers.

\section{Model validation}

This model is first compared to FEA (Finite Element Analysis) and afterward an experimental validation is performed by a proposed setup.

1) FEA: The FEA is based on models of both fingers constituted by a tip suspended with fixed-fixed compliant beams (see Fig. 11). The preload is generated by introducing a displacement of one sensor after that apparent stiffness is calculated $\left(K_{y}=1000 \mathrm{~N} / \mathrm{m}\right)$. Then, a lateral contact force is applied and the displacement of the compliant parts is deduced. Gripping forces are constructed based on $F_{y i}=F_{y i 0}$ $+K_{y} \cdot \Delta_{y i}$. The result is shown in Fig. 12.

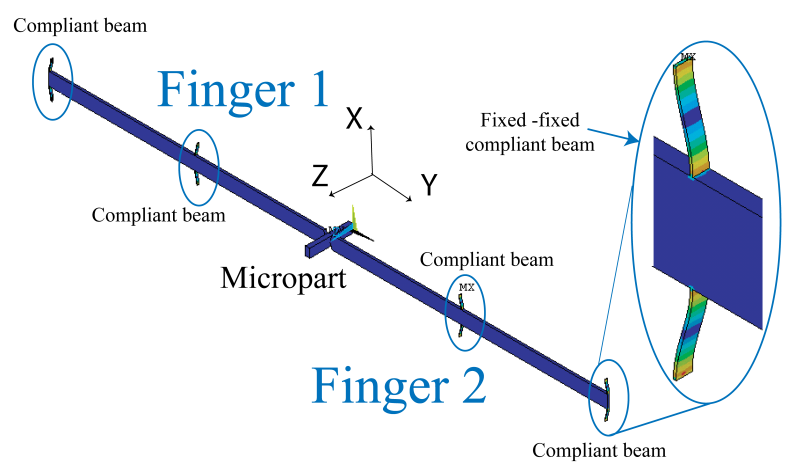

Fig. 11. Model with the compliant parts of the considered force sensor used for FEA.

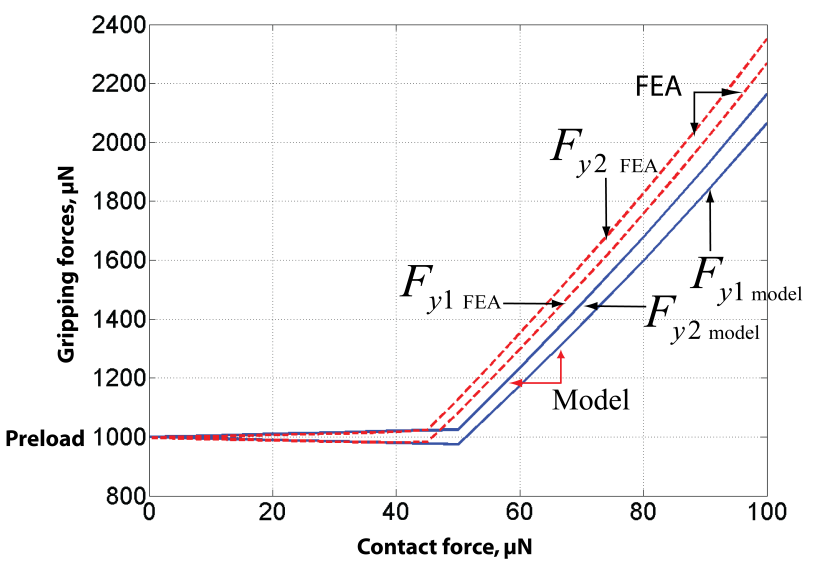

Fig. 12. FEA results compared to the model with parameters: $F_{y 10}=$ $F_{y 20}=1000 \mu \mathrm{N}, \ell=975 \mu \mathrm{m}, w_{m}=100 \mu \mathrm{m}, t_{f}=50 \mu \mathrm{m}, K_{y}=1000 \mathrm{~N} / \mathrm{m}, \mathrm{E}=170$ $\mathrm{GPa}, L_{p}=3000 \mu \mathrm{m}, w_{p}=300 \mu \mathrm{m}$.

The difference between the model and FEA is estimated at $9 \%$ for $F_{y}=100 \mu \mathrm{N}$.

2) Experimental validation: The objective is to measure gripping forces according to the applied lateral contact force. We propose a validation setup (Fig. 13) which uses a microgripper with two-sensing-fingers based on capacitive force sensors S270 from FemtoTools (www.femtotools.com). These compact probe sensors have a measuring range of \pm 2000 $\mu \mathrm{N}$ with $0.4 \mu \mathrm{N}$ in resolution. Each finger can move in $Y$ to ensure the open/close motion of the microgripper. Here, they are mounted on $X_{i} Y_{i} Z_{i}$ stages. To ensure the alignment 
of the probe, pitch and yaw ( $\alpha$ and $\beta$ ) are controlled. A movable substrate is mounted on the $X_{c} Y_{c} Z_{c}$ coarse stage. The kinematic scheme of the setup is presented in Fig. 14.

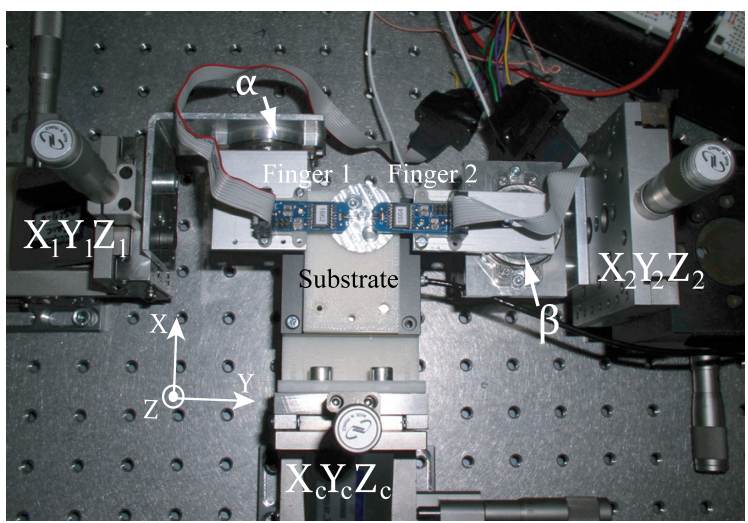

Fig. 13. Setup with two-sensing-fingers based on S270 FemtoTools.

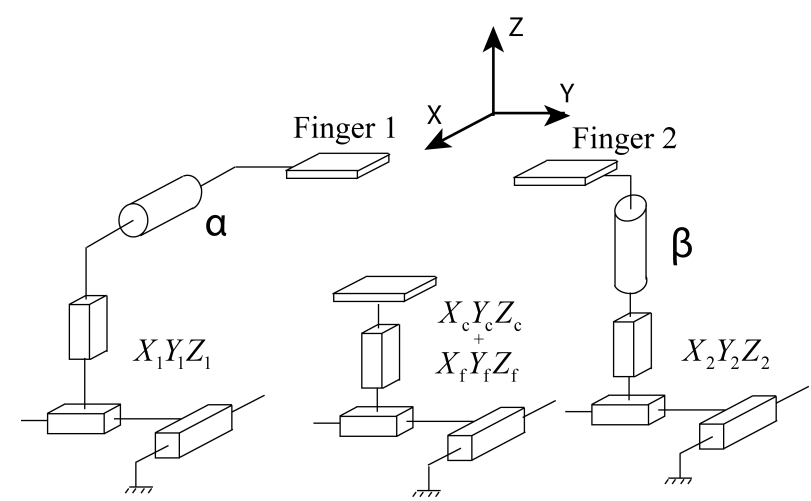

Fig. 14. Kinematic scheme of the proposed setup.

A third force sensor is used to generate a known external force used for model validation. Due to the obstruction of the two fingers of the microgripper, it is not possible to use a conventional S270 for the third force sensor. The modification of the sensor design by placing the active part of the sensor at $90^{\circ}$. The read out circuit and the active part are bought separately. They are assembled manually in our lab. This technique requires welding and calibration of the obtained new sensor (called "perpendicular sensor"). It is shown in Fig. 15. The calibration of this perpendicular sensor is done with a conventional $S 270$ force sensor and permits to establish its sensitivity which is $S_{p s}=1743 \mu \mathrm{N} / \mathrm{V}$ in the studied case. Once calibrated, this sensor is mounted on the fine motorized stage $X_{f} Y_{f} Z_{f}$ after modifying a previous setup. The validation setup is shown in Fig. 16.
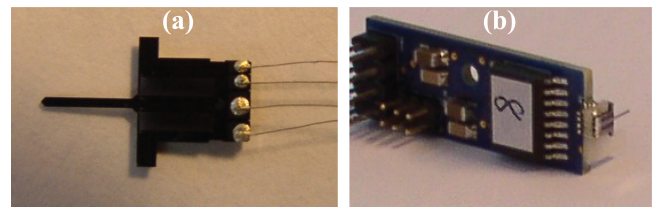

Fig. 15. (a) active part with wires and (b) assembled in $90^{\circ}$ with the readout circuit.
To perform the validation, the following sequence is established:

- the coarse alignment of the two fingers is performed by using two views from a camera,

- the micropart is grasped and the preload is controlled by fine positioning $Y_{1}$ or $Y_{2}$ on one finger,

- the lateral contact force is applied with the perpendicular force sensor by moving $Y_{f}$ and the evolution of the gripping forces is observed.

During the experimental validation, the misalignment (angle $\alpha_{x}$ and $\alpha_{z}$ ) has to be minimized in order to observe three steps correctly. In fact, the model is based on the perfect case where the misalignment between two fingers does not exist. This consideration is realistic due to the increasing number of microgrippers monolithically made [24], [35], [15].

The distance of contact $\ell$ is estimated at $1500 \pm 50 \mu \mathrm{m}$. The

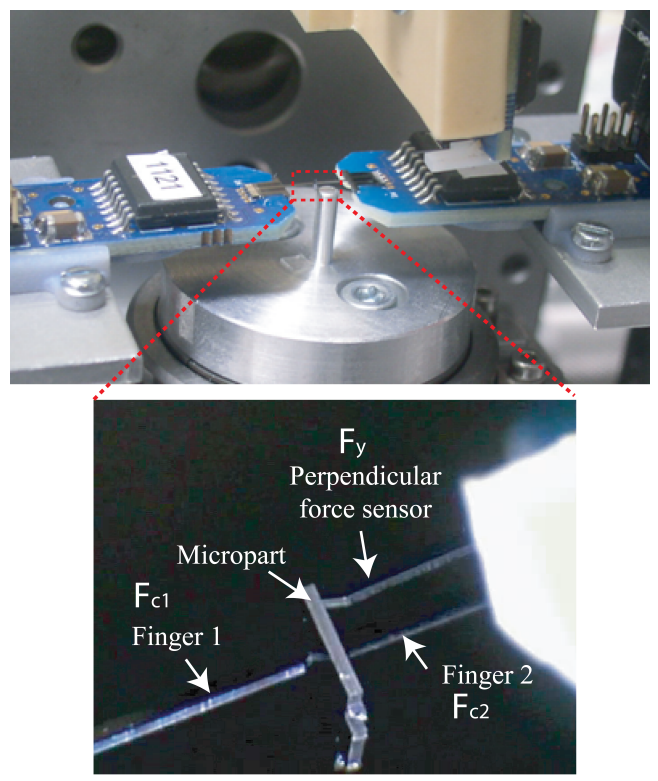

Fig. 16. Setup validation based on two-sensing-fingers.

uncertainty of the offset along $\mathrm{Z}$ is estimated at $\pm 5 \mu \mathrm{m}$ and induces an apparent thickness $t_{f a}=50 \pm 5 \mu \mathrm{m}$. The noise measurement is about $\pm 10 \mu \mathrm{N}$ and a low pass filter with 25 $\mathrm{Hz}$ of cut off frequency is used to reduce this electrical noise. Experimental results are shown in Fig. $17\left(F_{y_{i}}=1035 \mu \mathrm{N}, \ell=\right.$ $1500 \mu \mathrm{m})$ and Fig. $18\left(F_{y_{i}}=950 \mu \mathrm{N}, \ell=950 \mu \mathrm{m}\right)$. Models fit experimental measurements notably when the contact force appears: Step 2 is observed up to the contact force limit around $30 \mu \mathrm{N}$ in Fig. 17 and $40 \mu \mathrm{N}$ in Fig. 18, when the lateral contact is bigger than the contact force limit, it is observed that gripping forces increase corresponding to Step 3.

\section{VARIATION OF MODEL PARAMETERS}

The proposed model suits the experimental validation and FEA. Next, we propose to investigate the effects of influent parameters on the variation of gripping forces in the presence of a lateral contact force. 


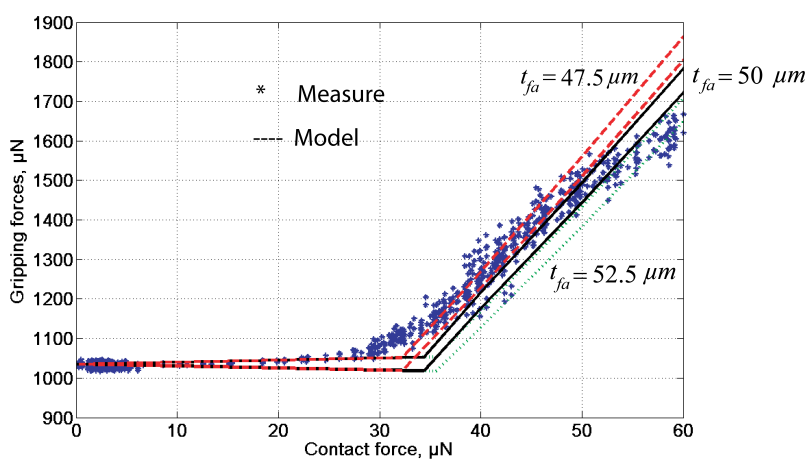

Fig. 17. Comparison between the model and experimental results with parameters: $F_{y 10}=F_{y 20}=1035 \mu \mathrm{N}, \ell=1500 \mu \mathrm{m}, w_{m}=100 \mu \mathrm{m}, t_{h a}=50$ $\pm 5 \mu \mathrm{m}, K_{y}=1000 \mathrm{~N} / \mathrm{m}, \mathrm{E}=170 \mathrm{GPa}, L_{p}=3000 \mu \mathrm{m}, w_{p}=300 \mu \mathrm{m}$.

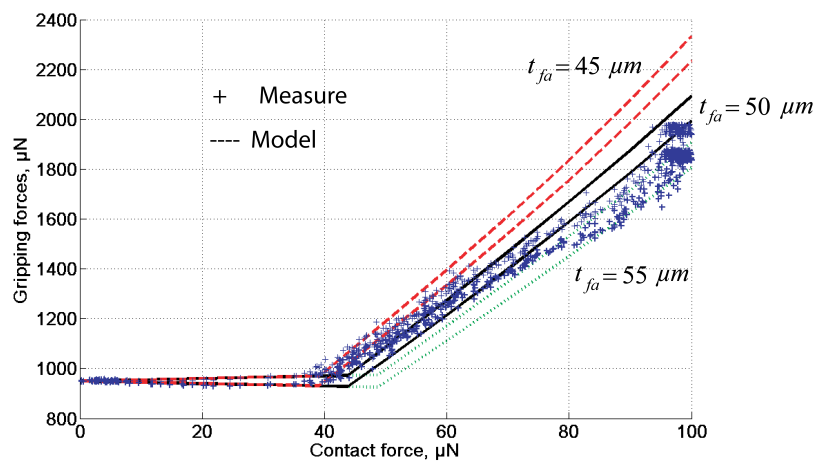

Fig. 18. Comparison between the model and experimental results with parameters: $F_{y 10}=F_{y 20}=950 \mu \mathrm{N}, \ell=950 \mu \mathrm{m}, w_{m}=100 \mu \mathrm{m}, t_{f a}=50 \pm 5$ $\mu \mathrm{m}, K_{y}=1000 \mathrm{~N} / \mathrm{m}, \mathrm{E}=170 \mathrm{GPa}, L_{p}=3000 \mu \mathrm{m}, w_{p}=300 \mu \mathrm{m}$.

\section{A. Effect of the tip thickness and offset along $Z$}

In the analytical model, we considered the tip thickness for perfect alignment of the probe. If we introduce an offset along $\mathrm{Z}$, the apparent thickness which is the distance between two edges of contact changes according to Fig. 19. Indeed an offset $d_{z}$ induces apparent thickness $t_{f a}=t_{f}+d_{z}$ when the contact is on the left side and $t_{f a}=t_{f}-d_{z}$ on the right side. The effect of tip thickness or offset along $\mathrm{Z}$ is studied and the variation of the model is investigated.

Results are presented in Fig. 20. When the apparent thickness
(1)

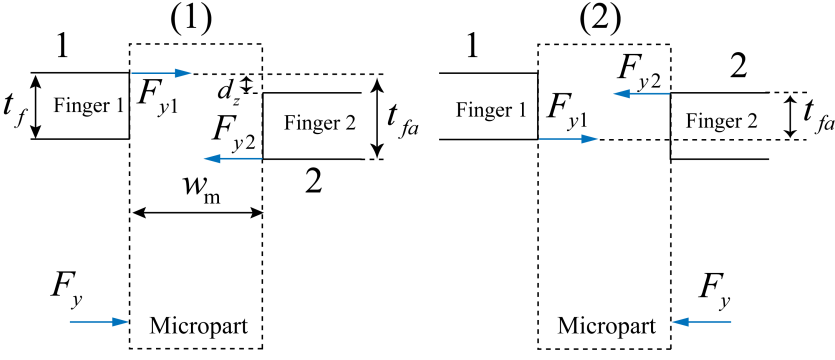

Fig. 19. Offset along $\mathrm{Z}$ and its consequence to the apparent thickness $t_{f a}$.

decreases, gripping forces increase for a given lateral contact force. Conversely, when the apparent thickness increases, gripping forces decrease. Variation of $F_{y \ell}$ is also observed

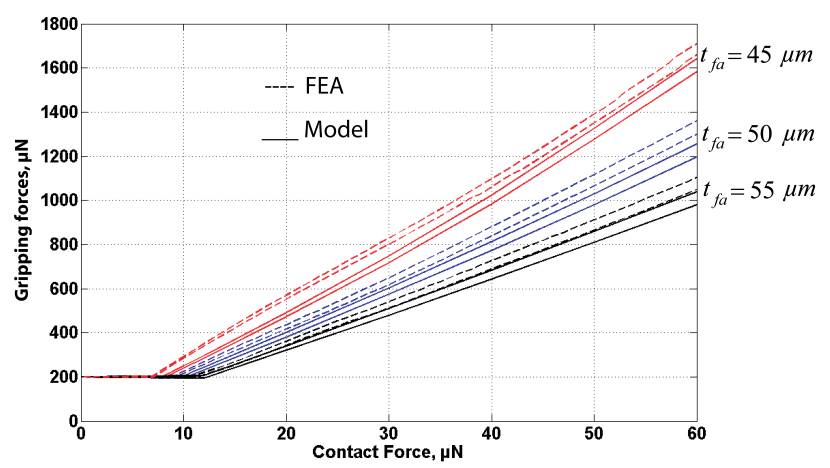

Fig. 20. Influence of the apparent thickness $t_{f a}$ on gripping forces evolution: $F_{y}$ with $F_{y 10}=F_{y 20}=200 \mu \mathrm{N}, \ell=975 \mu \mathrm{m}, w_{m}=100 \mu \mathrm{m}, t_{f a}=50 \pm 5 \mu \mathrm{m}$, $K_{y}=1000 \mathrm{~N} / \mathrm{m}, \mathrm{E}=170 \mathrm{GPa}, L_{p}=3000 \mu \mathrm{m}, w_{p}=300 \mu \mathrm{m}$.

according to (6).

\section{B. Effect of contact distance $\ell$}

The variation of the contact distance is also investigated. Results are shown in Fig. 21. It was observed that increasing

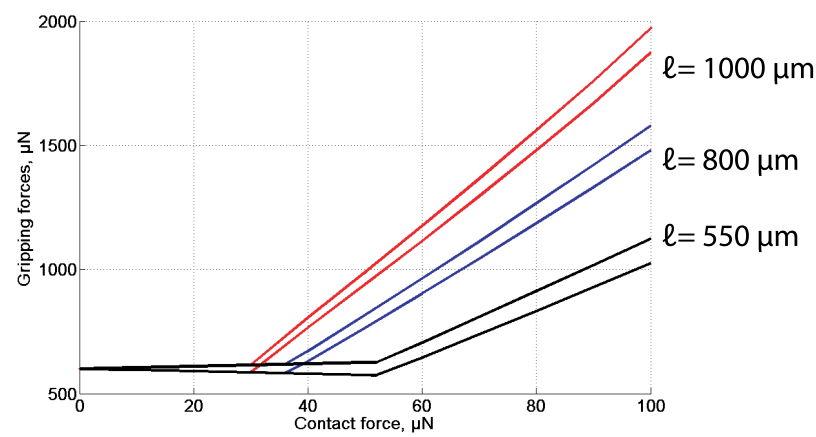

Fig. 21. Influence of the contact distance $\ell$ on gripping forces evolution: $F_{y 10}=F_{y 20}=600 \mu \mathrm{N}, \ell=1000,800,550 \mu \mathrm{m}, w_{m}=100 \mu \mathrm{m}, t_{f}=50 \mu \mathrm{m}$, $K_{y}=1000 \mathrm{~N} / \mathrm{m}, \mathrm{E}=170 \mathrm{GPa}, L_{p}=3000 \mu \mathrm{m}, w_{p}=300 \mu \mathrm{m}$.

$\ell$ introduces a bigger slope on gripping forces and reduces the lateral contact force limit according to (6). The experimental validation of the effect of $\ell$ is proposed. The result is shown in Fig. 22 and it is observed that the influence of $\ell$ corresponds to the proposed model i.e. the variation of the slope during Step 3 in accordance to $\ell$.

\section{Effect of the preload}

To perform grasping, a preload force is applied to the micropart. This preload enables a micropart to be held between fingers. The effect of the preload is studied in the presence of a lateral contact force and the result is depicted on Fig. 23. The variation of the contact force limit (6) is observed. Curves demonstrate that the slope variation during Step 3 is not consistent. Experimental validations are performed to validate these results. It is observed that the force limit varies according to the preload and the slope variation during Step 3 is not consistent. Experimental results are shown in Fig. 24. 


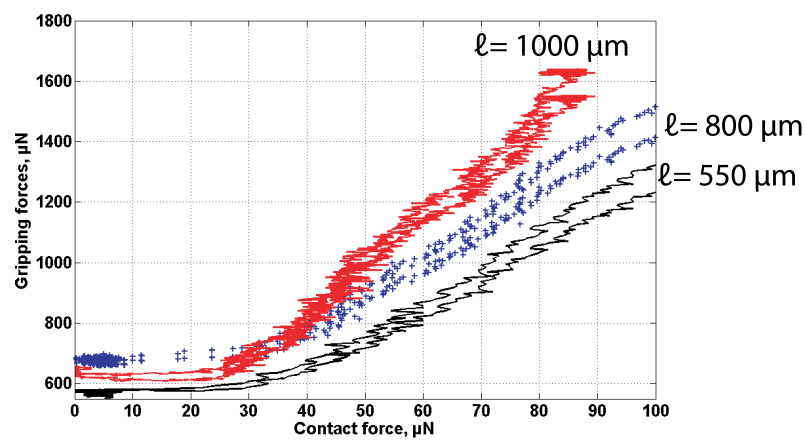

Fig. 22. Experimental results showing the effect of the contact distance $\ell$ : $F_{y 10}=F_{y 20}=600 \pm 50 \mu \mathrm{N}, \ell=1000,800,550 \mu \mathrm{m}, w_{m}=100 \mu \mathrm{m}, t_{f}=50$ $\mu \mathrm{m}, K_{y}=1000 \mathrm{~N} / \mathrm{m}, \mathrm{E}=170 \mathrm{GPa}, L_{p}=3000 \mu \mathrm{m}, w_{p}=300 \mu \mathrm{m}$.

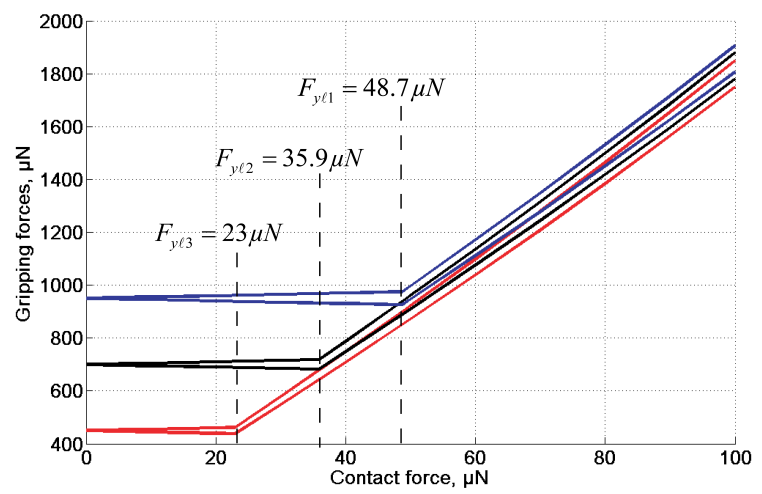

Fig. 23. Results based on the model of preload effect at $F_{y 10}=F_{y 20}=950$, $700,450 \mu \mathrm{N}$ with $\ell=950 \mu \mathrm{m}, t_{f}=50 \mu \mathrm{m}, w_{m}=100 \mu \mathrm{m}, K_{y}=1000 \mathrm{~N} / \mathrm{m}$, $\mathrm{E}=170 \mathrm{GPa}, L_{p}=3000 \mu \mathrm{m}, w_{p}=300 \mu \mathrm{m}$.

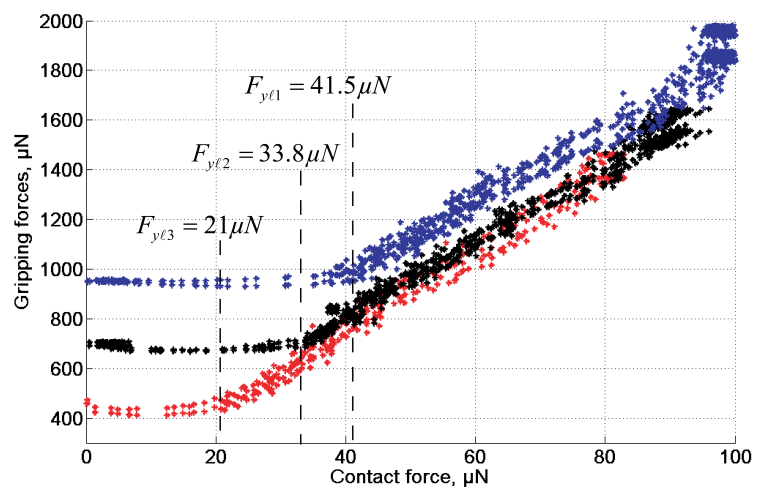

Fig. 24. Experimental results of preload effect with $\ell=950 \mu \mathrm{m}, t_{f}=50 \mu \mathrm{m}$, $w_{m}=100 \mu \mathrm{m}, K_{y}=1000 \mathrm{~N} / \mathrm{m}, \mathrm{E}=170 \mathrm{GPa}, L_{p}=3000 \mu \mathrm{m}, w_{p}=300 \mu \mathrm{m}$.

\section{Effect of the stiffness of the probe $K_{y}$ and $K_{z}$}

For the microgripper design, the stiffness has to be chosen thus its influence is studied. The stiffness along the sensing axis is firstly studied. It was shown that this stiffness influences the evolution of gripping forces for three compared values as shown in Fig. 25( $\left.K_{y}=200 \mathrm{~N} / \mathrm{m}, 1000 \mathrm{~N} / \mathrm{m}, 2000 \mathrm{~N} / \mathrm{m}\right)$.

The stiffness along $\mathrm{Z}$ influences the evolution of gripping forces. The value of the stiffness $K_{z}$ is modified in the model and three values are proposed $\left(K_{z}=129 \mathrm{~N} / \mathrm{m}, K_{z}=26 \mathrm{~N} / \mathrm{m}\right.$,

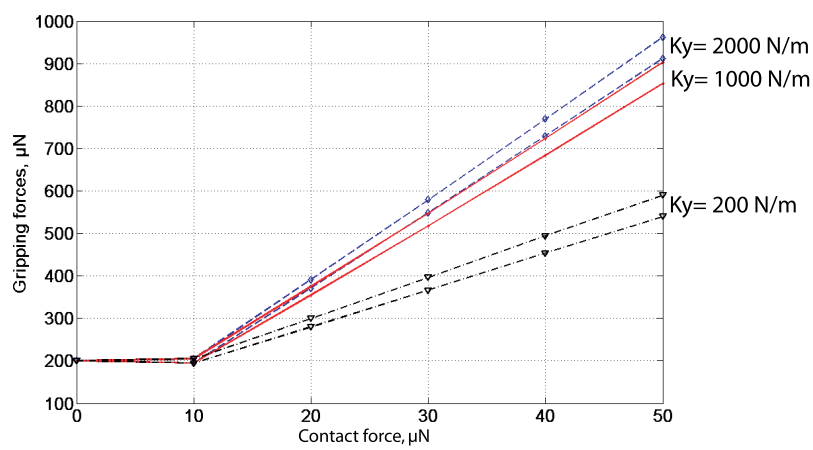

Fig. 25. Results of $K_{y}$ stiffness effect: $K_{y}=200 \mathrm{~N} / \mathrm{m}, K_{y}=1000 \mathrm{~N} / \mathrm{m}$, $K_{y}=2000 \mathrm{~N} / \mathrm{m}$.

$K_{z}=10 \mathrm{~N} / \mathrm{m}$ ). Results of the variation of the gripping force are shown in Fig. 26.

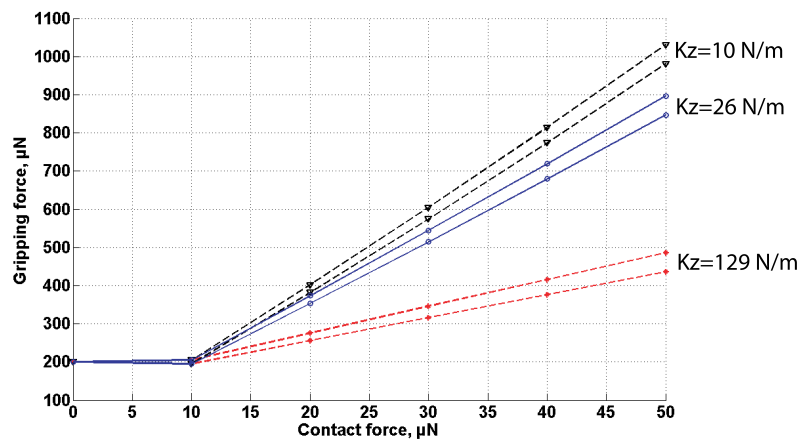

Fig. 26. Results of $K_{z}$ stiffness effect: $K_{z}=129 \mathrm{~N} / \mathrm{m}, K_{z}=26 \mathrm{~N} / \mathrm{m}, K_{z}=10$ $\mathrm{N} / \mathrm{m}$.

\section{CONSEQUENCES ON THE MICROGRIPPER DESIGN AND FORCE RANGE FOR MICRO-ASSEMBLY}

\section{A. Effect of ratio $t_{f} / \ell$ on gripping force evolution}

The main objective of control gripping is to preserve the manipulated object. Moreover, the appearance of lateral contact force induces gripping force variation and the expression of the lateral contact force limit which separates plane/plane contact and edge-vertex contact is given by (16).

$$
F_{y \ell}=F_{y_{0}} \frac{2 t_{f}}{2 \ell+t_{f}}
$$

If we consider the $x=\frac{t_{f}}{\ell}$ variable,

$$
F_{y \ell}=F_{y_{0}} \frac{2 x}{2+x}
$$

The study of these variations shows two steps of micropart motion. These two steps are separated by the limit of contact force. Considering a fixed preload force, the variation of this limit force depends on the thickness of the probe $t_{f}$ and the distance of contact $\ell$. Taking into account the possible thickness of the microgripper in the range of 25 to $100 \mu \mathrm{m}$ and the length of the micropart from 200 to $2000 \mu \mathrm{m}$, the variation of the contact force limit according to the ratio $x=\frac{t_{f}}{\ell}$ is shown 
in Fig. 27. It is observed that $x$ varies from $\frac{\min \left(t_{f}\right)}{\max (\ell)}$ to $\frac{\max \left(t_{f}\right)}{\min (\ell)}$. The variation of contact force limit seems linear according to $x$. This conducts to the statement 1: "when the manipulated

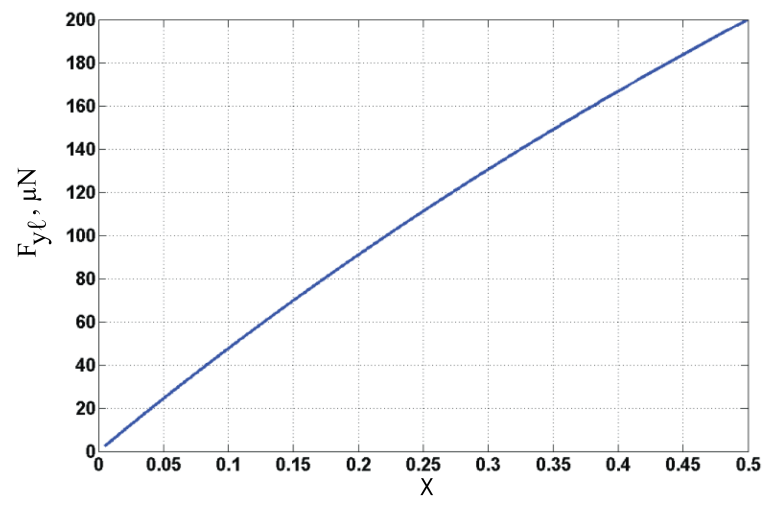

Fig. 27. Lateral contact force limit $F_{y}$ evolution according to the ratio $x=$ $\frac{t_{f}}{\ell}$ with $F_{y 10}=F_{y 20}=500 \mu \mathrm{N}$.

micropart is subjected to a lateral contact force, gripping forces $\left(F_{y 1}, F_{y 2}\right)$ can be limited by extending plane/plane contact (i.e. Step 2) by increasing the $\frac{t_{f}}{\ell}$ ratio".

\section{B. Compliance choice}

The variation of the stiffness along the axis of the grasp $\mathrm{Y}$ and along the perpendicular axis to the lateral contact force $(Z)$ shows that they influence gripping forces during edge - vertex contact (Step 3) (see Fig. 25 and Fig. 26). Consequently, we establish the statement 2: "To decrease the slope of gripping forces during edge-vertex contact, rigid behavior of the microgripper along the perpendicular axis to the lateral contact force $(Z)$ and flexible behavior along the axis of the grasp $(Y)$ have to be designed". In subsection III-B, the relation between the displacement of contact point $\Delta_{y F}$ and the lateral contact force $F_{y}$ is formulated. Compliance of the microgripper determines the displacement of the micropart in the presence of a lateral contact (i.e. $\theta$ depends on $\Delta_{y 1,2}$, $\Delta_{z}$, and $\left.\Delta_{y F}\right)$. In the case that maximum gripping forces have to be controlled for fixed $\Delta_{y F}$ during Step 3, the analytical model enables to define the compliance of the microgripper in accordance to $\Delta_{y F}$ and $F_{y 1 \max } / F_{y 2 \max }$. In this aim, we indicate statement 3: "The microgripper's behavior $\left(K_{y}, K_{z}\right)$ can be designed for the maximum defined displacement of contact point $\Delta_{y F}$ in order to limit gripping forces".

\section{Influence of the preload}

During micro-assembly, the unwanted displacement of manipulated microparts has to be limited. The objective is to avoid the loss of the micropart (sliding, ejecting) and to guarantee the coordinate frame of the task. The preload directly acts on the expression of the contact force limit as seen in (16). Consequently, the displacement of the micropart can be limited by extending Step 2 (plane/plane contact). In addition, planar contact between the micropart and the probe enhances the stability of the micropart in the presence of a perturbation force along $X$ and $Z\left(F_{x_{\text {pert }}}, F_{z_{\text {pert }}}\right)$ [33]. We therefore obtain statement 4: "The preload applied to the micropart during micro-assembly has to be set at a maximum value for extending plane/plane contact (for fixed $\frac{t_{f}}{\ell}$ ratio) which limits the displacement of the micropart in the presence of a lateral contact and improves the stability in the presence of a perturbation force". This value has to be limited to avoid indentation and deposition which depends on $\frac{\text { applied force }}{\text { surface in contact }}$ ratio.

\section{CONCLUSiON}

In this paper, a microgripper based on two-sensing-fingers ensuring the grasp during micro-assembly is presented. Force range during tasks like picking is provided for microparts with a size smaller than $0.1 \mathrm{~mm}^{3}$. An analytical model of the evolution of the gripping forces in the presence of a lateral contact force is proposed. This model is based on static equations of the force/torque equilibrium in the $Y Z$ plane, a pseudorigid body and the non sliding of the micropart between the two fingers of the microgripper. Validations are done by FEA and experimental measurements using a proposed microrobotic setup based on two-sensing-fingers providing a force sensing in the range of $\pm 2 \mathrm{mN}$ and $0.4 \mu \mathrm{N}$ in resolution. The proposed $2 \mathrm{D}$ model gives the evolution of gripping forces smaller than $10 \%$ of difference compared to FEA and experimental measurement for $100 \mu \mathrm{N}$ of lateral contact force. The evolution of contact (plane/plane contact, edge-vertex contact) between the micropart and fingers is also observed by FEA and validated by experimental results. The analytical model is generic thus it can be extended to other microgrippers. The effects of parameters variation are investigated and experimental results confirm the proposed model. In accordance to task constraints, statements are established on the microgripper design and the applied force range which can reach $3 \mathrm{mN}$ during microassembly. They concern the thickness of the probe, contact type between the probe and micropart, compliance, applied preload for limiting gripping forces and micropart displacement. In the presence of a lateral contact force, it is possible to define microgripper features $\left(t_{f}, K_{y}, K_{z}\right)$ to limit the variation of gripping forces. It was shown that the alignment of two fingers and the offset along $Z$ are important thus gripper based on two-fingers fabricated monolithically is the best choice. The established force range during micro-assembly leads to the choice of a microgripper actuator able to generate a blocking force in the $\mathrm{mN}$ range. In addition, the model and the proposed experimental setup constitutes a useful tool for understanding micropart displacement subjected to external perturbations. This study will enable to achieve the active control of the position of the micropart based on gripping forces information. The study of flexible micropart perturbated by lateral contact could also be a perspective of these works.

\section{ACKNOWLEDGMENT}

These works have been partially funded by the French region Franche-Comte. We would like to acknowledge Micky Rakotondrabe for discussions and David Guibert for technical support. 


\section{REFERENCES}

[1] D. Tolfree and M. J. Jackson, Commercializing Micro-Nanotechnology Products. CRC Press, 2006.

[2] N. Dechev, W. Cleghorn, and J. Mills, "Microassembly of 3-d microstructures using a compliant, passive microgripper,' IEEE/ASME Journal of Microelectromechanical Systems, vol. 13, pp. 176 - 189, 2004.

[3] A. N. Das, J. Sin, D. O. Popa, and H. E. Stephanou, "On the precision alignment and hybrid assembly aspects in manufacturing of a microspectrometer,' IEEE Conference on Automation Science and Engineering (CASE), 2008.

[4] S. Bargiel, K. Rabenorosoa, C. Clévy, C. Gorecki, and P. Lutz, "Towards the high accuracy assembly of hybrid moems components on a reconfigurable silicon free-space micro-optical bench," Journal of Micromechanics and Microengineering (JMM), vol. 20, pp. 1-12, 2010.

[5] J. Agnus, P. Nectoux, and N. Chaillet, "Overview of microgrippers and design of a micromanipulation station based on a mmoc microgripper," in IEEE International Symposium on Computational Intelligence in Robotics and Automation (CIRA), 2005.

[6] Q. Zhou, P. Korhonen, J. Laitinen, and S. Sjovall, "Automatic dextrous microhandling based on a 6-dof microgripper," Journal of Micromechatronics, vol. 3, pp. 359-387, 2006.

[7] D. Lang, "A study of micro-gripping technologies," Ph.D. dissertation, University of Southern Denmark, 2008.

[8] M. Savia and H. N. Koivo, "Contact micromanipulation - survey of strategies," ASME/IEEE Transaction on Mechatronics, vol. 14, pp. 504 514, 2009.

[9] B. Tamadazte, S. Dembélé, and N. L. Fort-Piat, "Robotic micromanipulation and microassembly using monoview and multiscale visual servoing," IEEE/ASME Transaction on Mechatronics, vol. PP, pp. 1-11, 2010 .

[10] M. Grossard, C. Rotinat-Libersa, N. Chaillet, and M. Boukallel, "Mechanical and control-oriented design of a monolithic piezoelectric microgripper using a new topological optimisation method," IEEE/ASME Transactions on Mechatronics, vol. 14, pp. 32-45, 2009.

[11] D. Hériban, J. Agnus, V. Petrini, and M. Gauthier, "A mechanical detethering technique for silicon mems etched with a drie process," Journal of Micromechanics and Microengineering (JMM), vol. 19, pp. 1-9, 2009.

[12] J. Park, S. Kim, D.-H. Kim, B. Kim, S. J. Kwon, J.-O. Park, and K.-I. Lee, "Identification and control of a sensorized microgripper for micromanipulation," IEEE/ASME Journal of Microelectromechanical Systems, vol. 10, pp. 601-606, 2005.

[13] M. Kohl, B. Krevet, and E. Just, "Sma microgripper system," Sensors and Actuators A: Physical (1), vol. 97-98, pp. 646-652, 2002.

[14] R. Pérez, J. Agnus, C. Clévy, A. Hubert, and N. Chaillet, "Modeling, fabrication, and validation of a high-performance 2-dof piezoactuator for micromanipulation," IEEE/ASME Transactions on Mechatronics, pp. 161-172, 2005 .

[15] F. Beyeler, A. Neild, S. Oberti, D. J. Bell, Y. Sun, J. Dual, and B. J. Nelson, "Monolithically fabricated microgripper with integrated force sensor for manipulating microobjects and biological cells aligned in an ultrasonic field," Journal of Microelectromechanical SystemS, vol. 16, pp. 7-16, 2007.

[16] F. Arai, D. Andou, Y. Nonoda, T. Fukuda, H. Iwata, and K. Itoigawa, "Integrated microendeffector for micromanipulation," IEEE/ASME Transactions on Mechatronics, vol. 3, pp. 17 - 23, 1998.

[17] Y. Shen, E. Winder, N. X, C. A. Pomeroy, and U. C. Wejinya, "Closed-loop optimal control-enabled piezoelectric microforce sensors," IEEE/ASME Transactions on Mechatronics, vol. 11, pp. 420-427, 2006

[18] C. C. Lan, C.-M. Lin, and C.-H. Fan, "A self-sensing microgripper module with wide handling ranges," IEEE/ASME Transactions on Mechatronics, vol. PP, pp. 1-10, 2010.

[19] M. Grossard, M. Boukallel, N. Chaillet, and C. Rotinat-Libersa, "Modeling and robust control strategy for a control-optimized piezoelectric microgripper," IEEE/ASME Transactions on Mechatronics, vol. PP, pp. 1-10, 2010.

[20] M. Boudaoud, Y. Haddab, and Y. L. Gorrec, "Modelling of a memsbased microgripper: application to dexterous micromanipulation," in IEEE/RSJ International Conference on Intelligent Robots and Systems (IROS), 2010.

[21] M. Rakotondrabe, K. Rabenorosoa, J. Agnus, and N. Chaillet, "Robust feedforward-feedback control of a nonlinear and oscillating 2-dof piezocantilever," IEEE Transactions on Automation Science and Engineering, Submitted.
[22] Z. Lu, P. C. Y. Chen, A. Ganapathy, G. Zhao, J. Nam, G. Yang, E. Burdet, C. Teo, Q. Meng, and W. Lin, "A force-feedback control system for micro-assembly," Journal of Micromechanics and Microengineering (JMM), vol. 16, pp. 1861-1868, 2006

[23] K. Rabenorosoa, C. Clévy, P. Lutz, M. Gauthier, and P. Rougeot, "Measurement of pull-off force for planar contact at the microscale," Micro Nano Letters, vol. 4, pp. 148 -154, 2009.

[24] M. C. Carrozza, A. Eisinberg, A. Menciassi, D. Campolo, S. Micera, and P. Dario, "Towards a force-controlled microgripper for assembling biomedical microdevice," Journal of Micromechanics and Microengineering (JMM), vol. 10, pp. 271-276, 2000.

[25] Y. Li, "Hybrid control approach to the peg-in hole problem," IEEE Robotics and Automation Magazine, vol. 4, pp. 52- 60, 1997.

[26] G. Yang, J. A. Gaines, and B. J. Nelson, "A flexible experimental workcell for efficient and reliable wafer-level 3d microassembly," in IEEE/RSJ International Conference on Robotics and Automation (IROS), 2001.

[27] Y. Yamamoto, T. Hashimoto, T. Okubo, and T. Itoh, "Measurement of force sensory information in ultraprecision assembly tasks," ASME/IEEE Transaction on Mechatronics, vol. 7, pp. 186-189, 2002.

[28] W. H. Lee, B. H. Kang, Y. S. Oh, and H. Stephanou, "Micropeg manipulation with a compliant microgripper," IEEE International Conference on Robotics and Automation (ICRA), 2003.

[29] Y. Zhou, B. J. Nelson, and B. Vikramaditya, "Fusing force and vision feedback for micromanipulation," in IEEE International Conference on Robotics and Automation (ICRA), 1998.

[30] Y. Shen, N. X. Li, and W. Y. Wang, "Dynamic performance enhancement of pvdf force sensor for micromanipulation," in IEEE/RSJ International Conference on Intelligent Robots and Systems (IROS), 2005.

[31] W. Zesch and R. S. Fearing, "Alignment of microparts using force controlled pushing," The International Society for Optical Engineering, vol. 3519, pp. 148-156, 1998.

[32] L. Zhou, J. M. Kahn, and K. S. J. Pister, "Corner-cube retroreflectors based on structure-assisted assembly for free-space optical communication," IEEE/ASME Journal of Microelectromechanical Systems, vol. 12, pp. 233-242, 2003.

[33] K. Rabenorosoa, C. Clévy, and P. Lutz, "Active force control for robotic micro-assembly: Application to guiding tasks," in IEEE International Conference on Robotics and Automation (ICRA), 2010.

[34] L. L. Howell, Compliant mechanisms. Wiley-Interscience, 2001.

[35] X. Liu, K. Kim, Y. Zhang, and Y. Sun, "Micronewton force-controlled manipulation of biomaterials using a monolithic mems microgripper with two-axis force feedback," in IEEE International Conference on Robotics and Automation (ICRA), 2008.

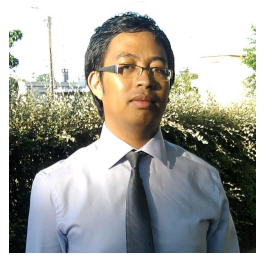

Kanty Rabenorosoa holds the Engineer degree (2007) in Electrical Engineering from Institut Nationale des Sciences Appliquées, Strasbourg, France and a Ph.D. in Automation and Computer Science (2010) from Université de Franche-Comté. He is currently a temporary research assistant at FEMTOST Institute in AS2M department (Automatic Control and Micro-Mechatronic Systems). His research interests are design, modeling and control of micromecatronic systems, and his application to robotic micro-assembly for MOEMS.

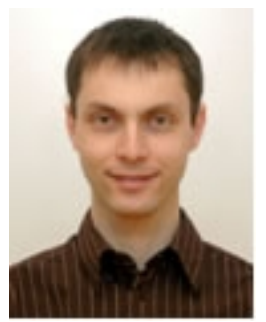

Cédric Clévy graduated from the Ecole Normale Supérieure de Cachan, France in 2001, received his master degree of Mechanical engineering and Automation in 2002 and his Ph.D. degree in Automation and Computer Science in 2005. Since 2006, he has been an Associate Professor at the University of Franche-Comté, Besançon, France working at the FEMTO-ST institute. His research interests are design and control of microrobotic, microfactories, micro-assembly systems oriented to optical components. 


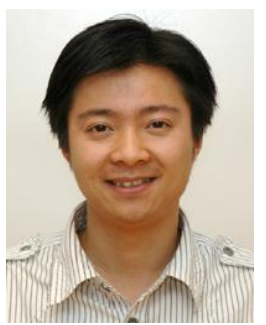

Qiao Chen received the Engineer degree from the National School of Mechanics and Microtechnology (ENSMM) in 2006 and the Ph.D. Degree of the University of Franche-Comté in Automation and Computer Science in 2010. His research interest is microrobotics, especially digital microrobots and microsystems control. He is currently research engineer for MEMS Medical Technology in Jinshan Group, China.

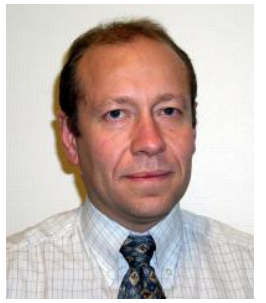

Philippe Lutz joined the University of FrancheComté,Besançon, as Professor in 2002. He is currently the head of the research group "Automated Systems for Micromanipulation and Microassembly" of the AS2M department of FEMTOST. He is the deputy director of the PhD graduate school of Engineering science. His research activities are focused on the design and the control of MicroMechatronic Systems. He teaches at the master level the design of Mechatronic Systems and Production System, and Control Theory.

He received the Engineer degree from the National School of Mechanics and Microtechnology (ENSMM) in 1990 and the Ph.D. Degree of the University of Franche-Comt in Automation and Computer Science in 1994. He was Associate Professor in the INSA of Strasbourg since 1994 until 2002. During this period, he has led the Mechatronics activities and developed research on inventive theory for solving problems. 